\title{
Stockholm Syndrome: Held Hostage by the One You Love
}

\author{
Matthew H. Logan, PhD
}

O N August 23, 1973, two machine-gun carrying criminals entered a bank in Stockholm, Sweden and took four hostages for $131 \mathrm{~h}$. The hostages were rescued 5 days later and despite threats and abuse, including being strapped with dynamite, they were surprisingly supportive of their captors. Amazingly, one woman later became engaged to one of the hostage takers and another developed a legal defense fund to assist their captors.

"Stockholm Syndrome" was the term given to this "bonding" that occurred (Bejerot 1974). In hostage negotiation it is defined as the psychological tendency of a hostage to bond with, identify with, or sympathize with his or her captor. Although there is no DSM or ICD diagnosis for either Stockholm Syndrome or Trauma Bonding it appears to be an unconscious emotional response to the terror of being captive and that protection is entirely in the hands of the captor or abuser. This puts the aggressor right where they want to be; in complete control.

Law enforcement personnel have long recognized this syndrome with battered women who fail to press charges, bail their battering partner out of jail, and even physically attack police officers when they arrive to rescue them. It is a rare phenomenon in crisis (hostage) negotiation and is seen in only $8 \%$ of victims taken hostage. Actual hostage situations are also quite rare with only $4 \%$ of police crisis negotiations involving "hostages." The other $96 \%$ involve either suicidal persons or barricaded subjects (HOBAS 2001).

The subject of Stockholm Syndrome gets far too much attention in the domain of hostage negotiation. I have been asked more questions about this phenomenon than any other element of negotiation and it received less than a page of my 204 page doctoral dissertation on crisis (hostage) negotiation (Logan 2001). The concept should receive more attention in the arena of domestic abuse and in the study of trauma. It is, in fact, represented in these domains under the title of Trauma Bonding and Narcissistic or Psychopathic Victim Abuse. These terms are much more descriptive and germane to those who are thriving despite having been in the grip of an abuser or those who currently are in an abusive relationship.

Trauma Bonding is evidenced in any relationship in which the connection defies logic and is very hard to break. The components necessary for a trauma bond to form are a power differential, intermittent good/bad treatment, and high arousal and bonding periods (Dutton and Painter
1993). This type of bonding can take place in concentration camps and kidnap experiences where the intense fear and will to survive can cause a bond with the enemy. This bonding is perpetuated by the imbalance of power and the manipulative nature of intermittent cycling of abuse with acts of kindness.

My perspective on this subject lightly touches the surface and my hope is to encourage research and discussion that will focus on reducing predatory behavior by the abusers and encouraging strategy formulation and a welcoming environment for those that have been ensnared and those who are still feeling despair and seeking relief.

To fully understand and evaluate the effect of this Trauma Bonding one would have to know the personality of both the abuser and the abused and the environment or context in which the bonding takes place. Context is a key as the high arousal of fear created by torture and various forms of abuse can be coupled with isolation and sensory deprivation.

\section{The Abuser or Captor}

In my experience the abusers are highly narcissistic, often psychopathic individuals, who use manipulation and cruelty to satisfy their own need for power and control. Comorbidity between Narcissistic Personality Disorder and Psychopathy is high and often it is the antisocial behavior with callousness, lack of empathy, and criminal versatility that sets the two apart. Narcissists typically display the charm, grandiosity, and conning/manipulative elements common to psychopathy, but they may not have the antisocial facet of the psychopath. Both share the selfish focus of need gratification and the desire to control others. As I have interviewed and diagnosed hundreds of psychopaths I always marvel at the ease and adept manipulation of a vulnerable person. The uncanny ability to sense a weakness or vulnerability in another person is followed closely by the charm of first impression and then buttressed by the promises of meeting the unmet needs of the other. The Stockholm Syndrome or Trauma Bonding in relationship does not come into play until Act II or until after the "capture" has taken place. It is after the veneer of first impression has worn thin that the "captor" now has to use the "good guy/ bad guy" scenario to set the bonding. Because the psychopath has the nasty combination of lack of empathy, callousness, and poor behavioral controls, he/she is able to 
play that "hard side/soft side" routine that is so necessary to the trauma bond forming (Hare and Logan 2007). Both the psychopath and the narcissist are adept at making the captive feel sorry for them by telling stories of their own abuse as children and making excuses for their temper and aggressive/assaultive behavior. This combined with small acts of kindness ingratiates them to the captive after the abuse that sets the fear of reprisal up in the captive. I have had cases as a police officer where this scenario played over and over and just when the captive gained the insight and strength to leave, the captor murdered the captive. "If I can't have you, nobody can" was the continual theme. In my last case with this scenario I was called as an expert in Bermuda to inform the court about the mindset of the perpetrator. After a 5-h interview of the accused it was obvious that he was psychopathic and had a long history of domestic violence and had "taken captive" four other women before the victim. Although he was far from being intelligent and sophisticated, he had used the above noted scenario to keep a woman with him and was increasingly frustrated when he lost every relationship after beating and controlling his captives for years. When the victim left him he stabbed her to death. Contrary to the defense assertions at trial, it was not Delusional Disorder with Morbid Jealousy but was a psychopathic killer who had counted on a "Stockholm" effect on his "captives" that he called his "girlfriends."

\section{The Abused or Hostage}

Now here is where it gets a bit difficult. It would be simple to say that all hostages or captives that fall prey to this type of person are "weak" or "needy." That is not the case; however, as we trace back as investigators we often find indicators that made the captives more susceptible to the wiles of the captor.

The attribution error allows us to transpose our beliefs about "normal" behavior onto those who behave differently. Too often we just shake our heads in disbelief as a captive returns to the captor voluntarily and despite the urgings not to by family and social supporters. Others throw up their hands and cite "Stockholm Syndrome" as the culprit without understanding the dynamics and the context of the situation.

Emotionally bonding with an abuser can actually be a strategy for survival for victims of abuse and intimidation. What might have begun as a normal relationship has turned into a controlling and abusive situation. They are trying to survive. Their personality is developing the feelings and thoughts needed to survive the situation and lower their emotional and physical risks. The fear of outbursts from the abuser becomes a controlling factor in the victim's life. For survival, the goal becomes to anticipate anything that may result in an outburst for the controlling person and avoiding it at all costs. The abused person becomes preoccupied with the needs, desires, and habits of the abusive controlling person. The outcome of this survival mode or "freeze" reaction versus "fight" or "flight" reaction can result in a captive who experiences a loss of self-esteem, selfconfidence, and psychological energy and who is "burned out" and too depressed to leave. Another possible outcome is a return to a childish infantile pattern of bonding with the aggressor.
In many cases, it's not simply feelings for a captor that keeps individuals captive in an unhealthy relationship_-it's the totality of the investment and the types of investment. Dr. Joseph Carver posted an article to his website in August, 2003 titled Love and Stockholm Syndrome: The Mystery of Loving an Abuser. It is an unpublished article that is a must read especially for family members who are trying to support a captive who exhibits trauma bonding. He offers both strategy and hope for supporters who feel isolated and rejected by the captive and the list of investments that further bonds the captive to the captor.

Emotional Investment-They've invested so many emotions, cried so much, and worried so much that they feel it necessary to see the relationship through to the finish.

Social Investment-They've got pride! To avoid social embarrassment and uncomfortable social situations, they remain in the relationship.

Family Investments-If children are present in the relationship, decisions regarding the relationship are clouded by the status and needs of the children.

Financial Investment-In many cases, the controlling and abusive partner has created a complex financial situation. Many captives remain in a bad relationship waiting for a better financial situation to develop that would make their departure and detachment easier.

Lifestyle Investment-Many controlling/abusive partners use money or a lifestyle as an investment. Captives in this situation may not want to lose their current lifestyle.

Intimacy Investment-They often invest emotional and sexual intimacy. Some captives have experienced a destruction of their emotional and/or sexual self-esteem in the unhealthy relationship. The abusing partner may threaten to spread rumors or tell intimate details or secrets. A type of blackmail using intimacy is often found in these situations.

The absence of strong, healthy early attachments robs people of the security necessary to interrupt the inner or social isolation that keeps them stuck in repetitive patterns. The good news is that, in contrast with victimized children, adults can learn to protect themselves and make conscious choices about not engaging in relationships or behaviors that are harmful (van der Kolk 1989). This is perhaps "easier said than done" as patterns are not easy to break. I am convinced that if a captive can catch a glimpse of a better life and summon the strength to leave the relationship, it is the change of context that will keep them from returning to the captor.

\section{The Environment or Context}

Context is the situation in which something happens and that can help explain it. I view it as the environment in which our senses engage and send us signals that can alter our affect and cognition which can result in a change of behavior. I have always loved a painting that I saw years ago and would love to be able to find a copy of it. It was a dark and stormy late evening and the rain was heavy, the clouds were black, and there was an angry river swollen with the recent rains. In the middle of the tumult was a farmer steering a large raft with a number of cows lying on the raft. The title of the painting was merely "Changing Pastures." It reminds me that when life or situation blows up a storm we can alter the context. Too often we are 
looking for the answers in the wrong place or we are locking ourselves down for "deep therapy" and the solution may be found in simply altering our environment.

I have spoken to a number of parents who have had a son or daughter in a relationship with a captor. Typically they have tried to talk their child into leaving the abusive relationship and have seemingly dug a deeper hole as the child has pushed them away. After understanding the dynamics and working through the usual avenues, I often ask "have you considered abduction?" Now I'm not espousing lawlessness; I'm simply saying "have you tried to change their context?" With one 19-year-old girl I was actively involved in having her boyfriend arrested and convincing her to change context from Canada to Europe. It was a difficult transition, very hard on the parent and the brave young woman. I am happy to say that 5 years later she is drug free, married, career focused, and back in Canada with a whole new mindset. She is a big believer in changing context to change the person. It took the contextual change to wake her consciousness up to the captive environment. Sometimes the solution is "changing pastures." We have too often disregarded the more simple solution of changing our physical environment and allowing our senses to experience peace. It is within the new context that we can then make sense out of the mayhem that we have exited.

Context often dictates reaction and one can see the difference in reaction by hostages of the 2002 Moscow Dubrovka House of Culture where the Russian government was seen as the evil force who rescued the hostages by sending in gas that ultimately led to the deaths of 125 of the hostages. In this case there was more sympathy for the captors than there is in other hostage situations. This is also evident in the dynamics of spousal abuse. Often the rescuer, whether it is social services, police, or family and friends, is seen as the evil entity, and the captor is viewed as the poor misunderstood victim. It is within the captor's best interest to keep his captive isolated and free from any support or influence that would undermine his absolute control over the captive.

Stockholm Syndrome can be found in any interpersonal relationships. The abuser may be in any role in which the abuser is in a position of control or authority. Corporate
Stockholm Syndrome is also alive and well in organizations where a boss or supervisor has this type of control over an employee. Typically there is a carrot dangling in front of the employee who believes that they will eventually benefit if they are compliant. Many are "frozen" into their roles because they lack the psychic energy to move on or "change pastures." Like rats on a treadmill they work for the captor who feeds them the scraps of kindness intermittently with the Kool-Aid of control.

An actual hostage situation is one where the hostage is being held as a bargaining chip so that the captor can get something in return. Relational hostage taking is far more common and again the captive is an object that satisfies the needs of the captor.

\section{Author Disclosure Statement}

No competing financial interests exist.

\section{References}

Bejerot N. (1974). The six day war in Stockholm. New Scientist. 61, 486-487.

Carver JM. Love and Stockholm Syndrome: The Mystery of Loving an Abuser. Unpublished document.

Dutton DG, Painter S. (1993). Emotional attachments in abusive relationships: A test of the traumatic bonding theory. Violence Vict. $8,105-120$.

Hare RD, Logan MH. (2007). Introducing psychopathy to policing. In Psychologie de l'enquête: Analyse du comportement et recherche de la vérité. M St-Yves, M Tanguay, eds. (Editions Yvon Blais, Quebec).

HOBAS (Hostage Barricade Database System). Statistics FBI. (2001). Logan MH. (2001). What hinders or facilitates successful crisis negotiation. Dissertation Abstracts UBC, 2001.

van der Kolk BA. (1989). The compulsion to repeat the trauma: Reenactment, revictimization, and masochism. Psychiatr Clin North Am. 12, 389-411.

Address correspondence to: Matthew H. Logan, PhD HALO Forensic Behavioural Specialists

E-mail: mattlogan6@gmail.com 